\title{
Teachers' Competency in Responding to the Needs of Learners with Barriers to Learning
}

\author{
Tlale, Lloyd Daniel Nkoli
}

\author{
University of South Africa, Department of Inclusive Education \\ University of South Africa (UNISA), PO Box 392 Pretoria 0003 \\ Emall: tlaleldn@unisa.ac.za
}

\author{
Doi:10.5901/mjss.2013.v4n13p143
}

\begin{abstract}
The government's decision to implement Inclusive had a range of challenges to facilitate smooth implementation. This required teachers to have specialised training, skills and competencies to adequately address the learning needs of learners with disabilities. Poorly trained and under-qualified teachers compromise not only the educational ethos but the overall organisation and application of inclusive education in our schools. The aim of this paper was to investigate whether teachers have necessary skills and knowledge in responding to the needs of learners with barriers to learning. Qualitative research was employed in this study. In this study, the interviews and group discussions were used to find out whether teachers' have necessary skills and knowledge in responding to the needs of learners with barriers to learning. Purposive sampling was used as a method of sample selection. Full service school primary teachers formed the core focus of the participants. The sample consisted of the teachers who are directly involved in the implementation of inclusive education.
\end{abstract}

Keywords: Inclusive Education; Barriers to learning; skills and Knowledge; Special Needs Education; Special School as a Resource Centre.

\section{Introduction}

The basic ideas of inclusive education can be found in many previous international policy documents. Some of the most prominent documents are the Convention on the Rights of the Child, the Jomtien World Declaration on Education for all, The Standard Rules on the Equalisation of Opportunities for Persons with Disabilities and the Salamanca Statement and Framework for Action adopted at the World Conference on Special Needs Education (Savolainen and Alasuutari, 2000: 10). The Convention on the Rights of the Child outlines the rights of all children and states that education shall prepare the child for an active adult life in a free society and foster respect for the child's parents, for his or her cultural identity, language and values of the cultural background and values of others (Savolainen and Alasuutari, 2000: 10).

The Jomtien Declaration's basic principles for promoting "Education for All" emphasise the inherent right of a child to a full cycle of primary education, commitment to a child-centred education where individual differences are accepted as a challenge and not as a problem, improvement of the quality of primary education, recognition of the wide diversity of needs and patterns of development among primary school children's individual needs and commitment to an integrated and holistic approach. The Standard Rules of the Equalization of Opportunities for Persons with Disabilities also stated that education for persons with disabilities should form an integral part of national educational planning, curriculum development and school organization. The Salamanca Framework for Action also asserts that schools should accommodate all children regardless of their physical, intellectual, social, emotional, linguistic or other conditions (Savolainen and Alasuutari, $2000: 11$-12).

The turning point for all South Africans that occurred in 1994 as a result of Democratic Elections and significant educational reforms, took place, characterized by a spirit of democracy. The Constitution, (Republic of South Africa, 1996: 7) founded our democratic state and common citizenship on the values of human dignity, the achievement of equality and the advancement of human rights and freedoms (Section (9)). The Constitution, (Republic of South Africa 1996:7-14), Section 29(1) and 9 (2, 3, 4 \& 5), further provide a special challenge to all of us by requiring that we give all learners the fundamental right to basic education addressing the imbalances of the past by focusing on the key issues of access, equity and redress.

Furthermore, all other policy documents and legislation that emerged, stressed the principles of social justice, quality education for all, the right to basic education, equality of opportunity and redress of past educational inequalities among those sections of the people who have suffered particular disadvantages or who are especially vulnerable, 
including street children, out-of-school youth, the disabled and citizens with special educational needs, illiterate women, rural communities and communities damaged by violence (South African Schools Act, 1996: 6). The current thinking on education for all means equal access to mainstream classroom activities.

\section{Literature Review}

\subsection{Responding to the needs of learners with barriers to learning}

All aspects of the curriculum need to be developed to ensure that the diverse needs of the learners are addressed. While some of this can be done at national and provincial levels through legislation, teachers at schools, in collaboration with parents, need to take this further on a practical level; to ensure that the needs of specific learners are met (Lazarus, Daniels and Engelbrecht, 2004: 51).

\subsection{Curriculum adaptation for learners with barriers to learning}

Despite many teachers' reservations regarding curriculum adaptation, Costello and Boyle (2013) argue that it is nothing more than good teaching, thereby implying that strategies that work for learners without barriers to learning will similarly work for learners with special educational needs. Implicitly then, the strategies that work for learners with special educational needs, will work for all other learners. Good teaching then means that learners, including learners with special educational needs, are supported in formulating realistic appraisals of themselves that facilitate the process of setting realistic life goals. The easiest and the most effective way of ensuring this is to view all the learners in a given class as lying on a continuum of learning. On the extreme left may be learners experiencing greater learning difficulties, while others are on the extreme right and needing extensive enrichment and challenges, with a large number of learners lying between these two ends. In this way, no qualitative distinction is made between learners with special educational needs and other learners (Coates, 2012).

Curriculum adaptation is, therefore, about recognizing individual learners' learning style and finding ways to employ this style most effectively in the learning situation. It must provide the setting and the climate in which learners can grow and develop their capacity, and criteria for selecting curricular content should be based on an understanding of the learners' barriers and needs. The greater the learner's learning difficulties, the more the teacher would need to act as a mediator between the learner, the environment and the learning content (Tailor and Harrington, 2003: 204).

Although curriculum adaptation cannot happen at home, what happens at school can be reinforced at home. Many of the values brought into the school system are learned at home and predict the learners' attitude towards learning. It is, therefore, important for parents to create a home environment that is supportive of learning both formally and informally. Communication and collaboration between teachers and parents therefore needs to happen continually as they support each other in making decisions regarding both the learners who need special educational needs and those who do not, in order to ultimately reinforce the skills, knowledge, values and attitudes being instilled at home and at school (Briggs and Sommerfeldt, 2003: 34).

\subsection{Addressing barriers to learning}

In reviewing a variety of literature, one realizes that every learner has a barrier of some kind. Department of Education (2001: 18) is of the opinion that learning breakdown happens when the learning needs of the learners are not met as a result of barriers to learning. According to Hallahan and Kauffman (2000: 6) emotional disturbances can also be a barrier to learning. When a learner has been orphaned, learning breakdown takes place and there is a likelihood that the learner might drop out of school. MacFarlane and Woolfson (2013) see loss of hope, financial problems, high levels of drug abuse, gangsterism, crime, teenage pregnancy, poor health care, lack of transport, high levels of stress, segregation, inadequate learning environment and negative attitude towards learning due to impairment as barriers to learning.

Traditionally, teachers referred learners with barriers to learning to special schools, as they did not see them as part of their lives. The success of inclusive education largely depends on teachers' perceptions towards inclusion and learners with barriers to learning.

Inclusive education policy applies not only to the acquisition of new skills but also to the new approach that teachers need to have towards teaching as a whole, and it is expected that it will eventually lead to successful implementation of inclusive education. In South Africa today, the challenge that faces the education fraternity is how to 
implement inclusive education successfully and effectively. Teachers need skills and knowledge to teach and achieve a good and healthy attitude towards their new way of teaching and circumstances that are facing them. This study therefore identified the teachers' perceptions about learners with barriers to learning and development and how this may affect the implementation of Inclusive Education.

\subsection{Development programmes for teachers}

Savolainen, Engelbrecht, Nel and Malinen (2012) argue that teachers and support providers must be equipped with the necessary skills and knowledge to promote appropriate attitudes so that they can respond to the needs of all learners. This should include effective development programmes that focus on re-training, orientation and pre- and in-service professional development, within a team approach. Appropriate and flexible forms of support for teachers working with learners with special educational needs should be the aim and result of policies. The availability of support from education specialists plays a crucial part, as it cannot be expected that all classroom teachers have the knowledge and expertise to meet every specific need. Policy makers must ensure that the content of teacher support systems is diverse and responsive to local level and individual needs.

In addition to being re-trained in curriculum and evaluation, teachers need to be trained to change their attitude of special needs children. Teachers can be trained to view those who do not fit into existing arrangements as offering surprises, that is, opportunities that invite further inventiveness (Department of Education, 2001: 6-7). This implies a more positive view of differences. Teachers must also be supported with appropriate materials. Lack of teaching/learning materials may hamper the quality of education. Teachers need support for their work in terms of information and background materials so that they can prepare their lessons and update their own knowledge. Also locally made learning/teaching materials can enhance considerably the quality of the learning/teaching process.

The implementation of the different types of support can incorporate a range of formats such as interactive presentations, small or large group discussions, applications during sessions and practice between sessions. It is posited that by addressing the stressors found to be associated with inclusion this will simultaneously enable teachers to develop a higher sense of efficacy. Such a support programme will provide teachers with a range of opportunities to gain knowledge about their own performance, to access further knowledge, and have appropriate opportunities to practice the skills and apply the knowledge in own classrooms. Regular meetings to discuss learner concerns will also provide opportunities to discuss and experience their own and others' struggles and challenges which are crucial to ensure participants that they are capable of successfully coping with inclusive education (Hay, Smit and Paulsen, 2001: 216).

\section{Research Methodology}

In this study qualitative design will be employed. Qualitative research gives the researcher a picture of what people think. The qualitative researcher often uses a sample or a smaller group of selected people and generalizes results to a larger group from which the smaller was chosen (Babbie, 2013). Qualitative was used to elicit the teachers' competency in responding to the needs of learners with barriers to learning. More detailed information on the essential aspects for successful implementation of teachers' competency in responding to the needs of learners with barriers to learning inclusive education was collected through the use of interviews and observations. The participants were purposively selected. All of the participants were mainstream primary school teachers who had attended inclusive education workshops and who were involved in its implementation. The selected schools could be seen as typical primary schools, which serve learners from lower socio-economic group.

The sample was homogeneous only in so far as that all the participants were primary school teachers involved in inclusive education classroom practice. These teachers were sampled because their attitudes, skills and knowledge have not been explored.

For the purpose of this study, a purposeful sampling strategy was used to participating individuals, because they were involved in the implementation of inclusive education. "The logic and power of purposeful sampling depends on selecting information-rich cases for study in depth. The information-rich cases are those from which one can learn a great deal about issues of central importance to the purpose of the inquiry" (Patton 2002:169). 


\section{Findings and Discussions}

\subsection{Teaching experience and qualifications}

All of the senior teachers indicated that inclusive education was not going to work no matter what effort is put into its implementation because teacher with regard to inclusion was inadequate. These teachers said that all the learners with challenges should be kept at the special schools. One teacher disputed that:

It took three years for me to be regarded as a qualified teacher. Is it enough to receive five day training and you are expected to make wonders?

While the Intermediate and Senior phase teachers were critical of inclusion, the Foundation phase teachers readily agreed with inclusive education White Paper 6 that all children can learn. They said that it is wrong to sideline learners who are experiencing barriers to learning. They indicated that all children have the right to education. Intermediate and senior phase teachers said that they are already overburdened with overcrowding and a lot of paperwork and added that a learner with challenges needs individualised support. Intermediate phase teacher commented that:

Foundation phase leaners are easy to accept changes than teenage intermediate and senior phase learners, who are at a stage of questioning the world, that is, they don't accept what you tell them. They believe in experimentation.

\subsection{Teachers' Level of Skills and Knowledge pose Barriers to Learning}

More qualified, experienced and older teachers indicated that lack of knowledge; experience and expertise are also regarded as barriers themselves, to help leaners who experience difficulties in class. From the interviews, it was evident that without the necessary training, skills, qualification and workshops, teachers are inclined to feel frustrated in responding to the needs of learners with barriers to learning. With regard to this one teacher emphasised his views in this manner:

Involving teachers through continuous workshops will help them fully understand what is expected out of them.... teachers need to be fully trained because they need to fully understand how to respond to the needs of learners with barriers to learning appropriately.

If proper training and support is not done, the teachers' efforts will not be realised, and learners will not benefit from an inclusive education setting. It is apparent that, without the necessary training, skills and knowledge, teachers are inclined to feel discouraged by the inclusion of all learners with barriers to learning.

\subsection{Professional Support for teachers}

The professionals were perceived as unsupportive to special schools and the teachers are worried that this may be worsened. As a result, teachers do not have much faith in the educational support services, and they appear to be receiving no assistance presently for the learners with barriers to learning. One of the teachers said:

The nearest hospital has the expertise of therapists, but they are too occupied to assist learners in the school. They may only assist the learners only if they come to the hospital, and the workload in the hospital is already putting them under pressure.

Presently, the district and provincial support teams are seen to be doing less in supporting teachers in their dilemma. Another teacher added that:

...Workshops, meetings, consultations in whatever means, those things are very important in bringing teachers on board, letting them to own and understand not only the learners but also to be able to comprehend the whole idea behind addressing barriers to learning.

Teachers believe that inclusive education can be successful when there is cooperation among the mainstream teachers, specialized personnel like therapists and education specialists from Department of Education. Teachers also went on further and said that they need expertise to work with learners who experience barriers to learning and that in- 
service training can help them a lot in this regard.

\section{Concluding Remarks}

Teachers agreed that there must be collaboration among the mainstream teachers, specialised personnel like therapists and education specialists from Department of Education for them to successfully address barriers to learning. Teachers also indicated that there was a need for more development with regard to knowledge and skills for all teachers. It is also necessary that teacher education and training should be revisited and designed to accommodate and support inclusion.

Teacher training institutions should incorporate the concept of inclusion as part of the curriculum. There should also be courses which are open to students from other programmes as well which indirectly help to prepare the student teachers to gain knowledge in relation to learners experiencing barriers to learning. As part of the teacher training programme, it is therefore recommended that education courses should make room for critical discussion regarding issues and concepts of inclusion and teaching effectiveness. The student teachers be given structured opportunities to experience inclusive education in practice. Exposure to observing teaching learners with special educational needs in inclusive setting is one of the essential components in the process of breaking down barriers to learning and building positive attitude towards inclusive education among teachers.

\section{References}

Babbie, E. (2013). The practice of social research. New York: Macmillan.

Beloin, K. \& Peterson, M., (1999). Teaching the inclusive teacher: restructuring the mainstreaming course in teacher education. Teacher Education and Special Education, 21 (4), 306-318.

Briggs, A. R. J. and Sommefeldt, D. (2003). Managing effective learning and teaching. London: SAGE.

Coates, J.K., (2012) Teaching inclusively: are secondary physical education student teachers sufficiently prepared to teach in inclusive environments?, Physical Education and Sport Pedagogy, 17:4, 349-365

Cochran-Smith, M., \& Lytle, S. L. (2009). Inquiry as stance: Practitioner research in the next generation. New York: Teachers College Press.

Costello, S and Boyle, C (2013) "Pre-service Secondary Teachers' Attitudes Towards Inclusive Education," Australian Journal of Teacher Education, 38 (4); 129-143

Hallahan, D.P. \& Kauffman, J.M. (2000). Exceptional learners: Introduction to special education. Boston: Allan \& Bacon.

Hay, J.F., Smit. J. \& Paulsen, M. (2001). Teacher preparedness for inclusive education. South African Journal of Education, 21(4): 213218.

Lazarus, S.; Daniels, B. \& Engelbrecht, L. (2004). The inclusive school. In P. Engelbrecht, L. Green; S. Naicker; L. Engelbrecht (Eds). Inclusive education in action in South Africa. Pretoria: Van Schaik.

MacFarlane, K \& Woolfson L.M. (2013). Teacher attitudes and behavior toward the inclusion of children with social, emotional and behavioral difficulties in mainstream schools: An application of the theory of planned behaviour. Teaching and Teacher Education 29: 46-52.

Patton, M. Q. (2002). Qualitative evaluation and research methods. London: Sage.

Savolainen, H.; \& Alasuutari H. (2000). Inclusion as an Internationally Recognised Policy. Juva: WSOY.

Savolainen, H., Engelbrecht, P., Mirna, N. \& Malinen, O. (2012). Understanding teachers' attitudes and self-efficacy in inclusive education: implications for pre-service and in-service teacher education, European Journal of Special Needs Education, 27:1,5168 ,

Tailor, G.R. \& Harrington, F.T. (2003). Educating the disabled. Enabling learners in inclusive settings. Oxford: Scarecrow Education.

The Constitution of the Republic of South Africa of 1996.

The South African Schools' Act of 1996. 
